\title{
Cutting of Origin and Insertion of Sternocleidomastoid Muscle for Treatment of Torticollis
}

\author{
AHMED ELSAYED ABOKRESHA, M.D. \\ The Department of Neurosurgery, Faculty of Medicine, Assiut University, Assiut, Egypt
}

\begin{abstract}
Background: Congenital Muscular Torticollis (CMT), caused by fibromatosis within the Sternocleidomastoid Muscle (SCM), cause cosmetic and functional problems which in turn can have an adverse impact on these patients in their adolescence and adulthood. Several operation have been used to release the SCM and the best technique is still controversial.

Aim of Study: We assessed the surgical results of bipolar release in 10 adult patients with uncorrected congenital muscular torticollis and more than 12 months of follow-up.

Patients and Methods: These patients underwent a bipolar release of the SCM and were retrospectively analyzed. The mean follow-up period was 14.9 months (range, 12-30). The mean age at time of surgery was 21 years (range, 18-24).

Results: The modified Lee's scoring system indicated excellent results in $3(30 \%)$ patients, good in $5(50 \%)$, and fair in $2(20 \%)$ at the last follow-up after surgery. The improvements in neck movement and head tilt were statistically significant $(p<0.05)$. The global satisfaction rating scale was 93.7\% (range, 90-100). No significant permanent complications occurred.
\end{abstract}

Conclusion: Bipolar release of the SCM is a safe and reliable technique for the treatment of CMT in adults.

Key Words: Congenital Torticollis - Adult - Sternocleidomastoid muscle - Tenotomy.

\section{Introduction}

CONGENITAL muscular torticollis (CMT), caused by fibromatosis within the Sternocleidomastoid Muscle (SCM), refers to unilateral contracture of the SCM that restricts the range of motion at the neck and causes a head tilt toward the shortened SCM [1,2]. Most infants with CMT are successfully managed with physical therapy $[3,4]$. However, the torticollis, when uncorrected or resisted, sometimes results in tightness of the SCM, limited neck motion, head tilt, and craniofa-

Correspondence to: Dr. Ahmed Elsayed Abokresha, E-Mail: Ahabokreshaa@gmail.com cial asymmetry. These cosmetic and functional problems can have an adverse impact on these patients in their adolescence and adulthood.

Several operation have been used to release the SCM: Uni-polar release, bipolar release, bipolar release with Z-plasty and endoscopic release [511]. The results of surgical release of the affected muscle for resistant cases are well recognized as good in infants, and even in older children $[2,12]$ However, CMT is diagnosed and treated when a patient is a infancy or child, and it reported rarely in adult; consequently, reports on the efficacy of surgery for the uncorrected cases are limited and the best technique is still controversial [13-20]

The aim of this study was to evaluated the results of bipolar release in 10 patients with CMT in adults with more than 12 months of follow-up.

\section{Material and Methods}

We retrospectively analyzed surgical outcomes of CMT in 10 adults whose bipolar release of the SCM was undertaken by a single neurosurgeon between 2014 and 2017. Each patient's wry neck had been noticed in infancy or early childhood by a parent. All patients met the following criteria: (1) Congenital muscular torticollis with head tilt on the affected side and the presence of a tight band in the ipsi-lateral SCM, with absence of any previous surgery; (2) Adult aged 18 years and older; and 3) No other congenital deformities in the neck. The patients were 4 males and 6 females. The right side was involved in 7 patients, and the left side in 3 . None of the patients presented with an additional congenital anomaly. The mean followup period was 14.9 months (range, 12-30). The mean age at the time of surgery was 21 years (range, 18-24). 
All patients underwent a uniform procedure using bipolar release of the SCM Fig. (1). The procedure was conducted while the patient was under intravenous anesthesia and supine. The patient's neck was extended with a sandbag, and then the patient's head was turned toward the shoulder on the opposite, uninvolved side. First, the distal portion of the SCM was released by making a skin incision 3 to $5 \mathrm{~cm}$ long on the medial end of the clavicle, with consideration given to palpable fibrous bands, and then deepening the incision to the tendons of the sternal and clavicular attachments of the SCM. The tight band and muscle tendon

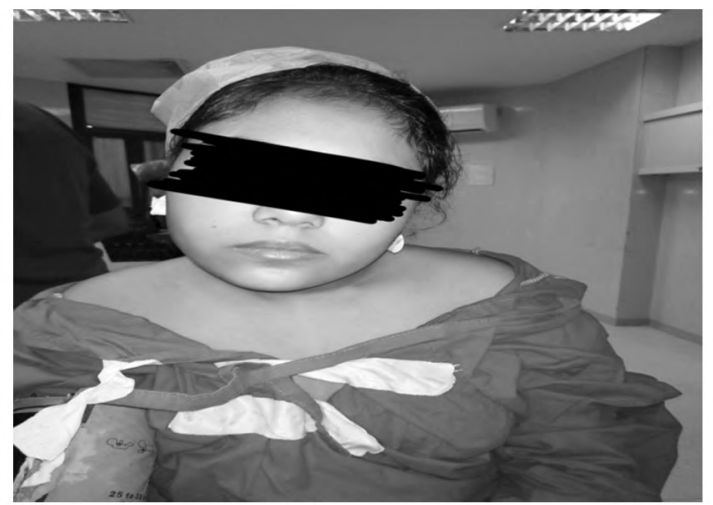

(A)

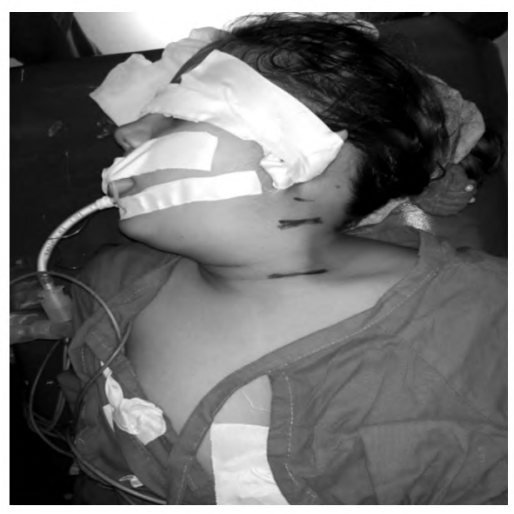

(C)

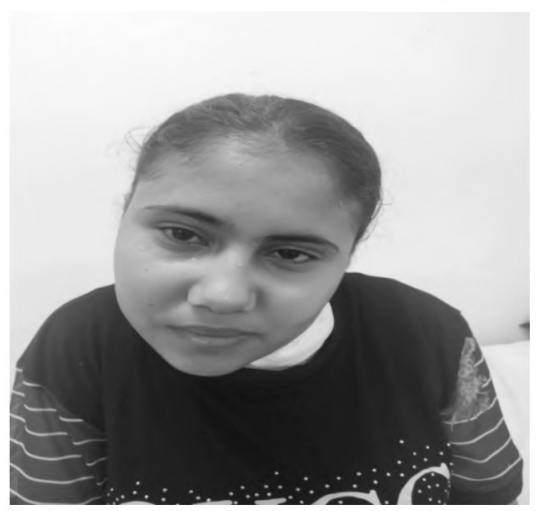

(F)

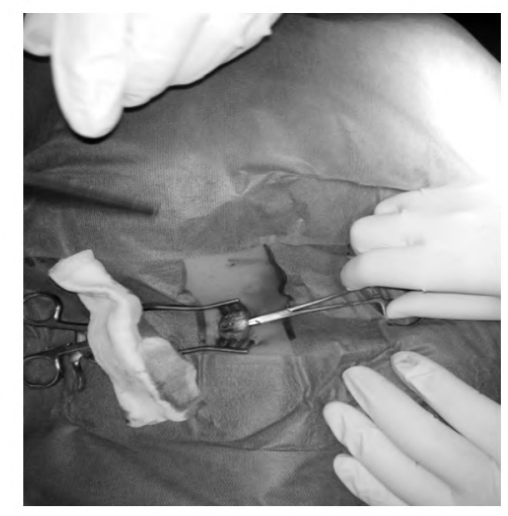

(D)

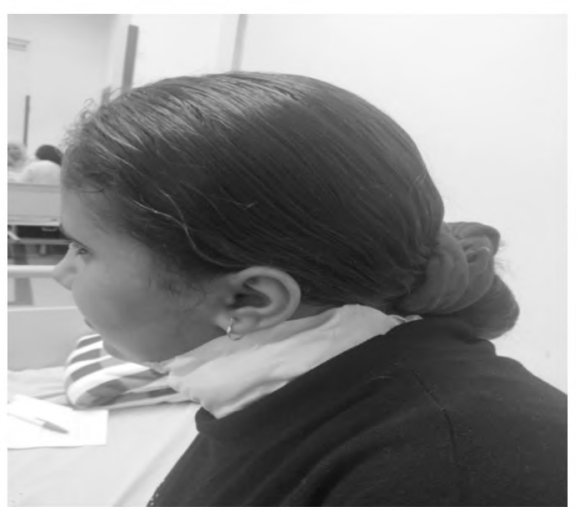

(G) were dissected to pass a right angle instrument posterior to the tendons and were then resected by electrocautery near the insertion site to the clavicle. Next, the proximal portion of the SCM was released by making a short transverse skin incision $1.5 \mathrm{~cm}$ to $2 \mathrm{~cm}$ long behind the ear, just distal to the tip of the mastoid process. The SCM was then carefully dissected and released near the bone, while checking the nearby nerves and vessels. Finally, the wound was closed with Vicryl 4-0 to approximate the subcutaneous tissues, with meticulous repair of the platysma, the skin was then closed with Vicryl 4-0.

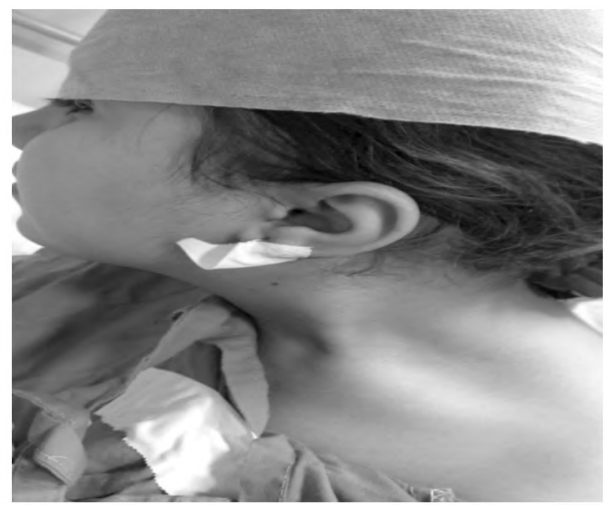

(B)

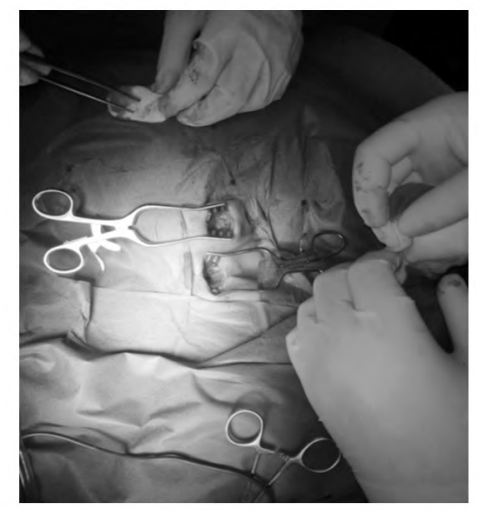

(E)

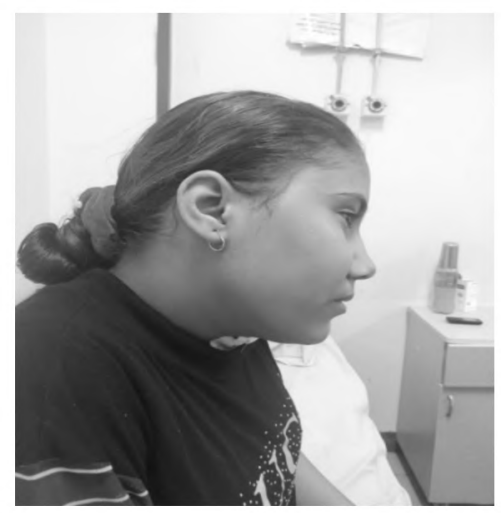

$(\mathrm{H})$

Fig. (1): A 18 year old girl with uncorrected congenital muscular torticollis. Her head is tilted toward the left. Pre-operative photograph (A, B), an Intraoperative photograph (C, D, E) and a post-operative photograph (F, G, H) of the same patient immediately after bipolar release, showing improvement of head tilt. 
A soft cervical collar was applied to maintain an upright position of the neck for at least 4 weeks after surgery. We recommended that each patient use the neck collar at home until 3 months after surgery. Each patient also received instructions for a manual stretching exercise and were directed to keep an upright position of the neck, while not wearing a brace, for at least 6 months. The intermittent stretching exercise was initiated 3 to 5 days after surgery.
Outcome assessment in our study was based on the modified Lee's scoring system [16] (Table 1) and global satisfaction rating scale using patient self-reporting. Craniofacial asymmetry was noted in all patients; however, because craniofacial remodeling is not expected in adulthood, we used the modified Lee's scoring system that excluded the facial asymmetry section from Lee's scoring system [18] for evaluation of the surgical outcome in our patients.

Table (1): Modified Lee's scoring system for assessment of adult muscular torticollis.

\begin{tabular}{|c|c|c|c|c|c|}
\hline \multicolumn{3}{|c|}{ Point Neck movement Head tilt } & \multirow{2}{*}{$\begin{array}{l}\text { Scar } \\
\text { Fine }\end{array}$} & \multirow{2}{*}{$\begin{array}{l}\text { Loss of column } \\
\text { None }\end{array}$} & \multirow{2}{*}{$\begin{array}{l}\text { Lateral band } \\
\text { None }\end{array}$} \\
\hline 3 & Full & None & & & \\
\hline 2 & $<10^{\circ} *$ & Mild & Slight & Slight & Slight \\
\hline 1 & $10-25^{\circ *}$ & Moderate & Moderate & Obvious but cosmetically acceptable & Obvious but cosmetically acceptable \\
\hline 0 & $>25^{\circ} *$ & Severe & Unacceptable & Unacceptable & Unacceptable \\
\hline
\end{tabular}

The outcomes of this modified scoring system, which included function (neck movement) and cosmesis (head tilt, operative scar, loss of column, and lateral band), were divided into the following four categories: An excellent result had a score of 14-15 points; good was $12-13$ points; fair was $10-$ 11 points; and poor was 9 or fewer points. The neck movement of rotation and lateral bending were measured clinically by physical therapists by comparing the contralateral side to the affected side. The head tilt, operative scar, loss of column, and lateral band were evaluated by clinical observation and a questionnaire.

Statistical analysis was performed using the Statistical Package for the Social Sciences (SPSS) software (ver. 12.0; SPSS). The statistical significance of the changes in neck movement deficit at last follow-up more than 1 year after surgery compared with the baseline was assessed using a paired $t$-test. A $p$-value $<0.05$ was considered statistically significant.

\section{Results}

The use of the modified Lee's scoring system gave excellent results for $3(30 \%)$ patients, good for $5(50 \%)$, and fair for $2(20 \%)$. Pre-operative limitation of movement in the neck was $10^{\circ}$ to $25^{\circ}$ in $5(50 \%)$ patients and above $25^{\circ}$ in $3(30 \%)$, which was improved to $10^{\circ}$ to $25^{\circ}$ in $2(20 \%)$ patients and below $10^{\circ}$ in $2(20 \%)$ after surgery. The pre-operative mean score of neck movement was $0.6 \pm 0.5$ (range, $0-1$ ), which was improved to $1.8 \pm 0.4$ (range, $1-2$ ). Pre-operative head tilt was mild in $2(20 \%)$ patients, moderate in $6(60 \%)$, and severe in $2(20 \%)$. Post-operative head tilt was rated as none in $8(80 \%)$ patients and mild in 2
(20\%). The pre-operative mean score of head tilt of $1.4 \pm 0.8$ (range, $0-2$ ) was improved to a mean of head tilt of $2.8 \pm 0.4$ (range, 2-3). These improvements in neck movement and head tilt were statistically significant $(p<0.05)$.

The appearance of scarring was fine in 7 (70\%) patients, slight in $2(20 \%)$, and moderate in 1 $(10 \%)$. Loss of column was rated as none in 7 (70\%) patients, slight in $2(20 \%)$, and obvious but cosmetically acceptable in $1(10 \%)$. The presence of a lateral band was rated as none in 4 (40\%) patients, slight in $5(50 \%)$, and obvious but cosmetically acceptable in $1(10 \%)$. The global satisfaction rating score using patient self-reporting was $93.7 \%$ (range, 90-100). A transient sensory deficit on the ipsilateral lower ear lobe was noted in two cases. The sensory problem dissipated nearly completely in three months. No wound infection, hematoma, or recurrence requiring surgery was encountered. No significant permanent complications occurred in any of the patients.

\section{Discussion}

Controversy still remains regarding the timing and the method of surgical correction of CMT, and the best surgical technique in adult patients (Table 2 ). The age of the patient is a major factor in the treatment of CMT. Manual stretching exercise was effective in about $95 \%$ of patients who were first seen before the age of 1 year [3,4]; however, CMT did not resolve spontaneously after 1 year of age $[2,19]$. Facial bone asymmetry started to appear after 5 years of age [20]. Any facial asymmetry could be prevented by surgery during early childhood, especially at 1 to 4 years of age, but the facial cosmetic result was unsatisfactory after 
surgery at over 6 years of age [12,21]. In contrast, other observations [22] found no difference in recovery of craniofacial asymmetry between a younger group ( 1 to 4 years old) and an older group (5 to 16 years old). And Ling [21] reported that patients above the age of 5 years more commonly encountered late complications, like loss of the sternomastoid column, disfiguring scars, and the presence of lateral bands.

Table (2): Comparative result of surgical release of congenital muscular torticollis in adults.

\begin{tabular}{|c|c|c|c|}
\hline \multicolumn{2}{|l|}{ Study } & $\begin{array}{c}\text { No. of } \\
\text { patients }\end{array}$ & Mean age (yr) \\
\hline \multicolumn{2}{|c|}{ Omidi-Kashani et al., [19] } & 14 & 21.9 (range, $18-32$ ) \\
\hline \multicolumn{2}{|l|}{ Patwardhan et al., [20] } & 12 & 24.0 (range, 17-31) \\
\hline \multicolumn{2}{|l|}{ Lim et al., [15] } & 37 & 27.4 (range, $18-48$ ) \\
\hline \multicolumn{2}{|l|}{ This study } & 31 & 30.3 (range, 20-58) \\
\hline Procedure & \multicolumn{3}{|c|}{ Result } \\
\hline Bipolar & \multicolumn{3}{|c|}{ Excellent 7 , good 5 , fair 0 , poor $2 *$} \\
\hline Bipolar with Z-plasty & \multicolumn{3}{|c|}{ Excellent 8, good 4, fair 0, poor $0 \dagger$} \\
\hline Unipolar and bipolar & \multicolumn{3}{|c|}{ Excellent 21 , good 12 , fair 4 , poor $0 \dagger$} \\
\hline Bipolar & \multicolumn{3}{|c|}{ Excellent 9 , good 18 , fair 4 , poor $0 *$} \\
\hline
\end{tabular}

The most popular surgical treatment for CMT consists of unipolar (distal) or bipolar (proximal and distal) release of the SCM. The extent of tightness of the SCM determines the choice of unipolar or bipolar release. The former is viewed as appropriate for early childhood and mild deformity, the latter may be indicated for older patients and more severe deformity [2,23]. Chen and Ko [5] recommended bipolar release as the treatment of choice for CMT in patients older than 6 years, whereas other authors [24] preferred to perform a distal release for patients older than 6 years. Lim et al., [14] reported that the site of release was determined intra-operatively, with bipolar release undertaken when manipulation could not give adequate correction after unipolar release, in order to reduce surgical morbidity in older children and adults. The rate of recurrence was almost $7 \%$ after distal release, while low 2 to $2.9 \%$ rate of recurrence was after bipolar release [3,25]. Ferkel et al., [6] described a modified bipolar release and Z-plasty, which can preserve the normal contour of the muscle in the neck; the clavicular head was released completely while the sternal head was lengthened by Z-plasty. This approach is especially helpful to avoid sunken appearance of the distal end of the SCM [2]. Patwardhan et al., [17] reported that bipolar release with Z-plasty in 12 adults with CMT preserved the neck line, but intraoperative estimation of the extent of lengthening was difficult. According to the Modified Lee scoring system, six patients had excellent results, two had good results and four had fair results. Some others [5] bipolar release with Z-plasty indicate higher risk of more tethering or insufficient release of fibrous bands when compared to unipolar or bipolar release without Zplasty. In the earlier study of bipolar release without Z-plasty, with meticulous repair of the platysma and soft tissues, loss of the neck column was not cosmetic problem $[\mathbf{5 , 1 6}]$.

We found excellent results in $30 \%$ of patients, good results in 50\%, and fair in $20 \%$ in this report. Neither significant complications nor recurrences were encountered.

These results are similar to those of a few authors who have reported benefits in the form of both cosmetic and functional improvements in the neck without serious complications after surgery in adult CMT patients $[13,15,16]$. In the present study, a bipolar release gave satisfactory results in the neck contour, with no loss of the lateral column of the muscle and with sufficient release of the lateral fibrous bands in most patients with meticulous repair of the platysma. Therefore, for adult CMT patients, we believe that a bipolar release without Z-plasty is less complicated and a simpler surgical treatment than bipolar release with Zplasty.

Bipolar release of CMT in most adults treated in this study improved the head tilt and underlying secondary cervical spinal changes, similar to previous work [13-16]. The adult patients adapted well to the new position of their necks. Their quality of life has improved dramatically since the operation, even in patients with irreversible craniofacial asymmetry. The high satisfaction rate above $90 \%$ obtained in this study is thought to reflect the good cosmetic benefit related to the head tilt and tight lateral band of the congenital disease through a relatively simple surgical release. The present result corresponds well with the earlier studies on children [23], which suggested that complete release of an abnormal tight fibrous band, even in adult patients with uncorrected CMT, is of critical importance.

Bipolar release of the SCM should be performed with caution to avoid injury the following major nerves and vessels: The facial and accessory nerves, internal and external jugular veins, and carotid artery $[\mathbf{1 0 , 2 5}]$. In this study, post-operative pain and hypesthesia were major complaints. A transient sensory deficit was noted on the inferior part of ipsilateral ear lobe in two cases, but this dissipated 
nearly completely in 3 months. During proximal release, this was caused by injury to the posterior and intermediate branches of the great auricular nerve supplying the skin over the mastoid process and on the back of the auricle.

Post-operative pain was markedly alleviated rapidly 3 days after surgery, resulting in a shortened hospital stay within 5 days after surgery and an earlier return to daily life activity in our patients.

Although a cast or halovest, cervical traction, and immobilization under overcorrected position were suggested for adult patients [13-15], we found that a more comfortable soft neck collar with early intermittent stretching exercise was sufficient to establish a neutral position of neck, in agreement with previous studies $[\mathbf{5 , 1 7}]$

\section{Conclusion:}

This study showed a statistically significant improvement of neck movement, head tilt, and lateral banding in most adult patients with CMT treated with biipolar release of the SCM. The patients were very satisfied with the functional and cosmetic results in the neck, even if their craniofacial asymmetry was unchanged, and none experienced any serious neurologic or spinal complications. Bipolar release of the SCM is therefore a safe and effective technique for the treatment of CMT in adults.

\section{References}

1- DO T.T.: Congenital muscular torticollis: Current concepts and review of treatment. Curr. Opin. Pediatr., 18: 26-9, 2006.

2- KELLY D.M.: Congenital anomalies of the trunk and upper extremity in Cannale S.T., Beaty J.H. (eds): Campbell's Operative Orthopaedics, ed 12. Philadelphia: Elsevier, Vol. 2, pp. 1119-32, 2013.

3- CANALE S.T., GRIFFIN D.W. and HUBBARD C.N.: Congenital muscular torticollis. A long-term follow-up. J. Bone Joint Surg. Am., 64: 810-6, 1982.

4- CHENG J.C., TANG S.P., CHEN T.M., WING M.W. and WONG E.M.: The clinical presentation and outcome of treatment of congenital muscular torticollis in infants-a study of 1,086 cases. J. Pediatr. Surg., 35: 1091-6, 2000.

5- CHEN C.E. and KO J.Y.: Surgical treatment of muscular torticollis for patients above 6 years of age. Arch. Orthop. Trauma. Surg., 120: 149-51, 2000.

6- FERKEL R.D., WESTIN G.W., DAWSON E.G. and OPPENHEIM W.L.: Muscular torticollis. A modified surgical approach. J. Bone Joint Surg. Am., 65: 894-900, 1983.

7- AMEMIYA M., KIKKAWA I., WATANABE H. and HOSHINO Y.: Outcome of treatment for congenital torticollis: A study on ages for treatment, treatment meth- ods, and post-operative therapy. Eur. J. Orthorp. Surg. Tramatol., 19: 303-7, 2009.

8- LEE T.G., RAH D.K. and KIM Y.O.: Endoscopic-assisted surgical correction for congenital muscular torticollis. J. Craniofac. Surg., 23: 1832-4, 2012.

10- YUAN B., QU F., ZHAO G., WANG J., SHEN X. and LIU Y.: Arthroscopic surgical treatment for neglected congenital muscular torticollis in adults. J. Craniofac. Surg., 26: 512-5, 2015.

11-ROMANS G.J.: The peripheral nervous system in Romans GJ (eds): Cun-ningham's textbook of anatomy, ed 12. Oxford: Oxford University Press, pp. 739-827, 1981.

12- ARSLAN H., GÜNDÜZ S., SUBA SI M., KESEMENLI C. and NECMIO GLU S.: Frontal cephalometric analysis in the evaluation of facial asymmetry in torticollis, and outcomes of bipolar release in patients over 6 years of age. Arch. Orthop. Trauma Surg., 122: 489-93, 2002.

13- IPPOLITO E. and TUDISCO C.: Idiopathic muscular torticollis in adults. Results of open sternocleidomastoid tenotomy. Arch. Orthop. Trauma. Surg., 105: 49-54, 1986.

14-LIM K.S., SHIM J.S. and LEE Y.S.: Is sternocleidomastoid muscle release effective in adults with neglected congenital muscular torticollis? Clin. Orthop. Relat. Res., 472: 12718, 2014.

15- OH I. and NOWACEK C.J.: Surgical release of congenital torticollis in adults. Clin. Orthop. Relat. Res., (131): 1415,1978 .

16- OMIDI-KASHANI F., HASANKHANI E.G., SHARIFI R. and MAZLUMI M.: Is surgery recommended in adults with neglected congenital muscular torticollis? A prospective study. BMC Musculoskelet. Disord., 9: 158, 2008.

17- PATWARDHAN S., SHYAM A.K., SANCHETI P., ARORA P., NAGDA T. and NAIK P.: Adult presentation of congenital muscular torticollis: A series of 12 patients treated with a bipolar release of sternocleidomastoid and Z-lengthening. J. Bone Joint Surg. Br., 93: 828-32, 2011.

18- LEE E.H., KANG Y.K. and BOSE K.: Surgical correction of muscular torticollis in the older child. J. Pediatr. Orthop., 6: 585-9, 1986.

19- COVENTRY M.B. and HARRIS L.E.: Congenital muscular torticollis in infancy; some observations regarding treatment. J. Bone Joint Surg. Am., 41: 815-22, 1959.

20- YU C.C., WONG F.H., LO L.J. and CHEN Y.R.: Craniofacial deformity in patients with uncorrected congenital muscular torticollis: An assessment from three-dimensional computed tomography imaging. Plast. Reconstr. Surg., 113: 24-33, 2004.

21- LING C.M.: The influence of age on the results of open sternomastoid tenotomy in musculartorticollis. Clin. Orthop. Relat. Res., (116): 142-8, 1976.

22- SHIM J.S. and JANG H.P.: Operative treatment of congenital torticollis. J. Bone Joint Surg. Br., 90: 934-9, 2008.

23- LEE I.J., LIM S.Y., SONG H.S. and PARK M.C.: Complete tight fibrous band release and resection in congenital muscular torticollis. J. Plast. Reconstr. Aesthet. Surg., 63: 947-53, 2010 
24- MINAMITANI K., INOUE A. and OKUNO T.: Results of surgical treatment of muscular torticollis for patients greater than 6 years of age. J. Pediatr. Orthop., 10: 7549, 1990.
25- WIRTH C.J., HAGENA F.W., WUELKER N. and SIEBERT W.E.: Biterminal tenotomy for the treatment of congenital muscular torticollis. Long-term results. J. Bone Joint. Surg. Am., 74: 427-34, 1992.

\title{
قطع آصل وإدخال عضلة القصية الترقوية القصبية فى علاج إعوجاج الرقبة
}

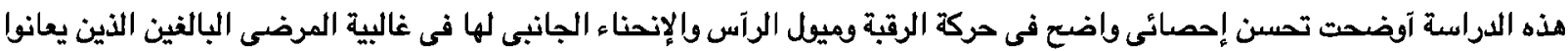 \\ من إنحناء الرقبة العضلى الخلقى والذين تم معالجتهم عن طريق قطع آصل وإدخال عضلة القصية الترقوية القصيبة. \\ المرضى كانوا مرضيين جداً بالنتائج التجميلية والوظيفية فى الرقبة حتى وإن كان التباين القحفى لم يتغير والمرضى لم يعانقا من آى \\ مشاكل عصبية خطيرة.
} وبالتالى فإن قطع آصل وإدخال عضلة القصية الترقوية القصبية يعثبر طريقة آمنة وفعالة فى علاج إنحناء الرقبة العضلى الخلقى. 